\title{
The Effects of Verbal Interactions on Individual and Team Performance in Engineering Design
}

\section{Dr. Muhsin Menekse, Purdue University, West Lafayette}

Muhsin Menekse is an assistant professor at the School of Engineering Education at Purdue University, with a joint appointment at the Department of Curriculum \& Instruction. Dr. Menekse's primary research investigates how classroom activities affect conceptual understanding in engineering and science for all students. His second research focus is on verbal interactions that can enhance productive discussions in collaborative learning settings. And his third research focus is on metacognition and its implications for learning. Much of this research focuses on learning processes in classroom settings. Dr. Menekse is the recipient of the 2014 William Elgin Wickenden Award by the American Society for Engineering Education.

\section{Dr. Senay Purzer, Purdue University, West Lafayette}

enay Purzer is an Associate Professor in the School of Engineering Education. Her research examines how engineering students approach innovation. She also studies informed design practices among college and pre-college students . She serves on the editorial boards of Science Education and the Journal of Pre-College Engineering Education (JPEER). 


\title{
The Effects of Verbal Interactions on Individual and Team Performance in Engineering
}

\begin{abstract}
Problem solving and decision-making, especially in team settings, is a critical but a challenging skill for engineering students. Discourse within groups can influence decision quality and learning outcomes. To investigate the relationship between individual contributions to discourse and team performance, this study explored the role of individual and team level factors as predictors of learning outcomes in a problem focused on sustainability. Audio and video data of engineering student teams have been coded for question, conflict, and reasoning episodes to explore the connection between team dynamics, quality of collaboration, and individual learning outcomes. These data were analyzed using a quantitative discourse analysis approach. We found that question type episodes has a significant impact on learning outcomes.
\end{abstract}

\section{Introduction}

Solving real-world problems require interpreting data and making decisions effectively. Even though decision-making in an uncertain decision situation with incomplete data is an essential skill across many domains, prior studies have shown even the experienced engineers and scientists have difficulty in eliminating alternatives and conducting successful decision analyses [1]-[3]. Problem solving and decision-making process become even more complex when decisions are made in small group settings. There is research evidence that group interactions and discourse processes can facilitate learning with reflection and co-construction of knowledge (e.g., [4] and individual achievement [5]). However, these verbal interactions may also prevent successful collaboration and lead to unproductive results (e.g., [6]). The purpose of this study was to examine the relationship between verbal interactions that occur in a team and the individual achievement and team performance. More specifically, the study explored:

1. To what degree the question, conflict, and reasoning episodes relate to students' individual performance?

2. What is the strength of association between verbal episodes and team performance?

\section{Literature Review}

In a group context, students engage in a number of different discourse episodes. These discourse moves may include question posing, sharing reasoning, disagreements, and elaborating on different ideas. Asking and answering questions has been connected to learning [7]. Questions stimulate shared construction of knowledge [8], [9]. In design literature questions are also linked to convergent and divergent thinking that are associated with innovative problem solving [10], [11].

Conflict episodes are also a topic of interest although their frequency in engineering classrooms has been found to be low [5]. Compared to response-, learning, and support-oriented discourse, challenge-oriented and disruptive discourse occur less frequently in the college classroom. According to Purzer [5] those students who gave support-oriented comments to their peers also 
had higher gains in their self-efficacy, which was then correlated with their individual achievement in a course. Other studies has also shown the critical role of supportive, friendly team environments in supporting student learning [12], [13].

Finally, studies also indicate evaluative comments and challenging ideas are important for learning (e.g., [14], [15]. Wall, Galanes, \& Love (1987) found a curvilinear relationship between the number of conflict episodes experienced by group members and the subsequent quality of their decisions [16].

While there are many studies that explore the relationship between student learning and group discourse, few have examined the role of verbal interactions in the context of engineering (e.g., [5], [17]. Hence, in this study we investigated the relationship between individual contributions and team performance in a decision-task associated with engineering and explored which individual and team level factors were significant predictors of learning outcomes in engineering domain.

\section{Methods}

\section{Research Participants}

The study sample included 73 first-year engineering students working in 19 teams. Each team included three or four students. Throughout the semester students worked in these teams and hence they were familiar with each other, and have a history of prior collaboration for working on different problems.

\section{Data Sources}

- Discourse moves. Student teams completed a performance task towards the end of the semester. The task included an information and data package and asked student teams to decide on the best system to reduce the energy consumption and cost of a town library (adding solar panels, installing a green roof, or making no changes to existing design) and make a recommendation to the client. The task also promoted students to document their problem scoping, their plan for managing time and team, explain the formulae for total system cost, construct a graphical representation for 10-year cost for current and new systems, and make decisions supported with justifications based on their calculations. Student had 60 minutes to complete the task. Teams produced brief written report and a spreadsheet. Team discourse and interactions, as they were working on this task, were videoand audio-recorded during the design task.

- Team performance. Using the written report and a spreadsheet teams has submitted, team performance on this task was evaluated. The evaluation focused on the quality of problem scoping, formulation of the solution, accuracy of the calculations, quality of graphical representations, and quality of their final decision.

- Individual performance. Students' scores on individual exams were used as the individual performance measure.

\section{Coding Process}


The first step was segmenting students' verbal data by the topic they discussed. The next step was identifying meaningful discourse episodes. Episodes may be as short as one utterance or as long as an entire conversation. For example, a question episode always had at least two utterances: a question and an answer; however, a reasoning episode may consist of only one statement. Two coders independently watched and listened team videos individually and coded for episodes and subcategories of each episode. Two coders scored nine team videos individually for verbal moves and the rest of the videos were scored only by one judge. The coders reached a high level of inter-rater reliability, one coder evaluated the rest of the data The Cronbach's alpha was .93 and the intraclass correlation was .87 for the nine videos that both judges scored. During the coding process, the coders identified types of utterances that made up meaningful chunks of discourse. These included: (1) an opening utterance as a specific episodic category based on the definitions presented below, (2) other members' reactions to the opening utterance (generally an answer, co-construction, or elaboration), and (3) the end of an episode (generally when the specific topic or problem is concluded or agreed upon).

\section{Verbal Coding Protocol}

A coding protocol, designed for this study, targeted three types of episodes: questions, conflicts, and reasoning (See Table 1). This coding protocol, its categories and rules, were developed based on the synthesis of three highly-cited protocols: 1) the conceptual knowledge elaboration scheme [18] $(, 2)$ the different communicative activities [19], and 3) the dialogue utterances [20].

The categories (questions, conflicts, and reasoning) is described below and detailed in Table 1 .

- Question episodes. Segments for question episodes generally began with a question and end with an answer. However, the episode may extend if a follow-up question is asked regarding or requesting further information about the previous answer. Questions could take the form of a statement when a question is implied.

- Conflict episodes. Segments for conflict episodes generally began with a response to a statement or action that presented conflicting opinions or understanding. These segments generally ended when the conflicting opinions or understandings were resolved and agreed upon.

- Conflicts elicited: Coded when one member asked a critical question, disagreed with another member, or did not verified a verification question using reasoning.

- Conflicts elaborated: Coded when mutual agreement is stated or implied after at least one argument.

- Reasoning episodes. Segments for reasoning episodes generally began with a statement concerning a particular topic or concept that conveys useful information for others. The episode was extended when additional statements from the same person or others served to supplement the initial statement. The segment could end in three ways: (1) no responses from others regarding the topic before a new topic is initiated, (2) general agreement ("okay"), or (3) with a conflicting statement rather than supplementing statement (which begins a "conflict episode"). Note: Any of the reasoning categories below that are followed by a verification question or tone will be considered continuation of a reasoning episode and 
not a verification question (or answer) as long as the question elicits further elaboration of the same topic.

- Individual: Reasoning or hypotheses produced by one member's statements alone.

- Co-constructed: Reasoning or hypotheses produced by collaboration between members.

Table 1. Coding Protocol for Question, Conflict, and Reasoning Episodes

\begin{tabular}{|c|c|c|c|}
\hline Episode & & Episode Sub-category & Examples \\
\hline \multirow{6}{*}{ 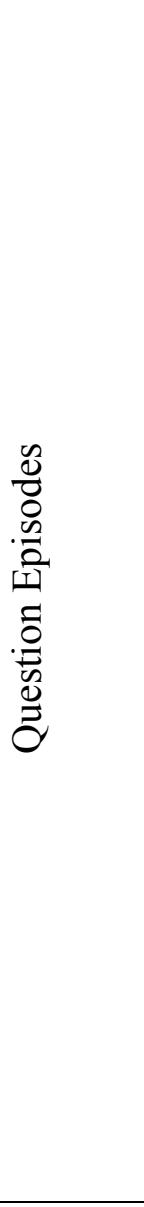 } & $\begin{array}{l}\text { Verification } \\
\text { questions }\end{array}$ & $\begin{array}{l}\text { Asking others to verify that information } \\
\text { or a course of action is correct. }\end{array}$ & $\begin{array}{l}\text { Has everyone had a chance } \\
\text { to read this? }\end{array}$ \\
\hline & $\begin{array}{l}\text { Search } \\
\text { questions }\end{array}$ & $\begin{array}{l}\text { Asking others to find and report } \\
\text { information taken from text, criteria, or } \\
\text { data. }\end{array}$ & $\begin{array}{l}\text { What was the cost for } \\
\text { maintenance? How big is } \\
\text { the roof? }\end{array}$ \\
\hline & $\begin{array}{l}\text { Open } \\
\text { questions }\end{array}$ & $\begin{array}{l}\text { Asking others for input on the next } \\
\text { course of action or for explanations to } \\
\text { fill lack of understanding. }\end{array}$ & $\begin{array}{l}\text { I don't understand how you } \\
\text { got this answer [implied: } \\
\text { can you explain?] }\end{array}$ \\
\hline & $\begin{array}{l}\text { Verification } \\
\text { answers }\end{array}$ & $\begin{array}{l}\text { Yes/no answers to verification } \\
\text { questions. If reasoning follows a yes/no } \\
\text { answer, the statement is coded as an } \\
\text { elaborated answer rather than a } \\
\text { verification answer. }\end{array}$ & Yeah \\
\hline & $\begin{array}{l}\text { Short } \\
\text { answers }\end{array}$ & $\begin{array}{l}\text { Reported information or knowledge } \\
\text { from text, criteria, or data given in } \\
\text { response to search questions. A short } \\
\text { answer may be non-verbal (i.e., by } \\
\text { pointing to the answer or showing it to } \\
\text { the questioner). }\end{array}$ & $\begin{array}{l}\text { It is here, the solar panels } \\
\text { are } 8 \text { by } 6 \text { feet. [showing the } \\
\text { information sheet] }\end{array}$ \\
\hline & $\begin{array}{l}\text { Elaborated } \\
\text { answers }\end{array}$ & $\begin{array}{l}\text { Explanations answering open questions } \\
\text { or reasoning added to verification } \\
\text { answers. Reasoning for negative } \\
\text { verification answers (i.e., a 'no' answer } \\
\text { with reasoning) is coded as a non- } \\
\text { verification conflict elicitation. }\end{array}$ & \\
\hline \multirow{3}{*}{ 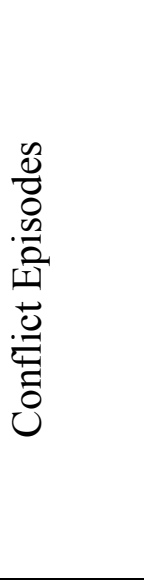 } & $\begin{array}{l}\text { Conflict } \\
\text { Elicited- } \\
\text { Critical } \\
\text { Question }\end{array}$ & $\begin{array}{l}\text { Question asked in a disconfirming } \\
\text { manner; elicitation of a counter- } \\
\text { argument through questioning. }\end{array}$ & $\begin{array}{l}\text { Shouldn't we be calculating } \\
\text { the number of solar panels } \\
\text { we're using first? }\end{array}$ \\
\hline & $\begin{array}{l}\text { Conflict } \\
\text { Elicited- } \\
\text { Counter- } \\
\text { argument }\end{array}$ & $\begin{array}{l}\text { Disagreement with a statement or course } \\
\text { of action of another. Only coded when it } \\
\text { is a response to a reasoning utterance or } \\
\text { an action. }\end{array}$ & $\begin{array}{l}\text { I don't think that's the final } \\
\text { cost though. }\end{array}$ \\
\hline & $\begin{array}{l}\text { Conflict } \\
\text { Elicited- } \\
\text { Non- } \\
\text { verification }\end{array}$ & $\begin{array}{l}\text { When a member does not verify that } \\
\text { information is correct AND gives } \\
\text { reasoning (of which will also be coded } \\
\text { under elaborated answers). }\end{array}$ & $\begin{array}{l}\text { [in response to verification } \\
\text { question] No, that's not the } \\
\text { right formula. }\end{array}$ \\
\hline
\end{tabular}




\begin{tabular}{|c|c|c|c|}
\hline & $\begin{array}{l}\text { Conflict } \\
\text { Elicited- } \\
\text { Support }\end{array}$ & $\begin{array}{l}\text { When another member in the group } \\
\text { supports any of the three categories } \\
\text { above. (Counts for involvement in } \\
\text { conflict episode but is not a separate } \\
\text { episode.) }\end{array}$ & \\
\hline & $\begin{array}{l}\text { Conflict } \\
\text { Elaborated- } \\
\text { Individual }\end{array}$ & $\begin{array}{l}\text { When a member provides an argument } \\
\text { after elicitation that everybody can then } \\
\text { agree on. If there is immediate } \\
\text { agreement after the initial conflict } \\
\text { elicitation, one point is coded for the } \\
\text { individual who elicited the conflict. }\end{array}$ & \\
\hline & $\begin{array}{l}\text { Conflict } \\
\text { Elaborated- } \\
\text { Collaborative }\end{array}$ & $\begin{array}{l}\text { When more than one member provides } \\
\text { an argument on the same topic before } \\
\text { agreement, each member who provides } \\
\text { an argument is given a point. }\end{array}$ & \\
\hline \multirow{3}{*}{ 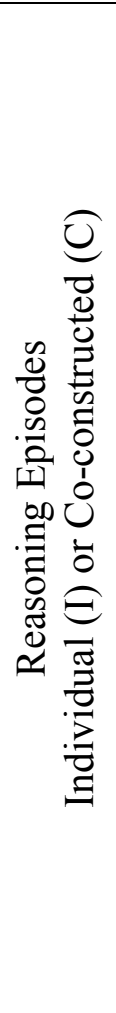 } & Observational & $\begin{array}{l}\text { Unelicited statements, general } \\
\text { reasoning, or reports information from } \\
\text { criteria, texts, or data. }\end{array}$ & $\begin{array}{l}\text { [I] If the units are in joules } \\
\text { then there should be a } \\
\text { formula to convert it. } \\
\text { [C] P1: This number is the } \\
\text { cost of maintenance per } \\
\text { year. P2: That will give us } \\
\text { part of the total cost. }\end{array}$ \\
\hline & Calculation & Verbal reports of calculation procedures. & $\begin{array}{l}\text { [I] The number of solar } \\
\text { panels can be found by } \\
\text { dividing } 1,200 \text { by } 48 . \\
\text { [C] } \mathrm{P} 1: \text { We just need to } \\
\text { divide 1,500 by } 30 . \mathrm{P} 2: \\
\text { Then multiply that by } 90 \text { to } \\
\text { find the energy cost. }\end{array}$ \\
\hline & Procedural & $\begin{array}{l}\text { Unelicited propositions about course of } \\
\text { action through reasoning or hypotheses. }\end{array}$ & $\begin{array}{l}{[\mathrm{I}] \text { This number is in square }} \\
\text { feet so we need to convert } \\
\text { meters to feet. } \\
\text { [C] P1: Now we have the } \\
\text { total cost for green roof. } \mathrm{P} 2 \text { : } \\
\text { So we just need to find the } \\
\text { total cost over } 10 \text { years. }\end{array}$ \\
\hline
\end{tabular}

\section{Data Analysis}

We also calculated percentages of discourse episodes to identify areas of common or weak occurrences. We conducted multilevel analysis by employing two-level hierarchical linear models- individual variables as level $1 \&$ team variables as level 2 . We conducted a multiple linear regression to investigate the relationship between verbal moves and students' individual performance. To examine the relation between with individual performance, team performance and verbal moves, we used Pearson product-moment correlation.

\section{Results}




\section{Distribution of Verbal Episodes by Team}

Figure 1 illustrates the distribution of discourse moves across teams. The student teams mostly engaged in reasoning episodes. Overall, approximately $52 \%$ of all episodes were reasoning episodes, $39 \%$ were question episodes, and $9 \%$ were conflict episodes. According to the fully unconditional hierarchical linear model, interclass correlation coefficient was .12, which indicates $12 \%$ of the variance is at group level, and the remaining $88 \%$ is at individual level.

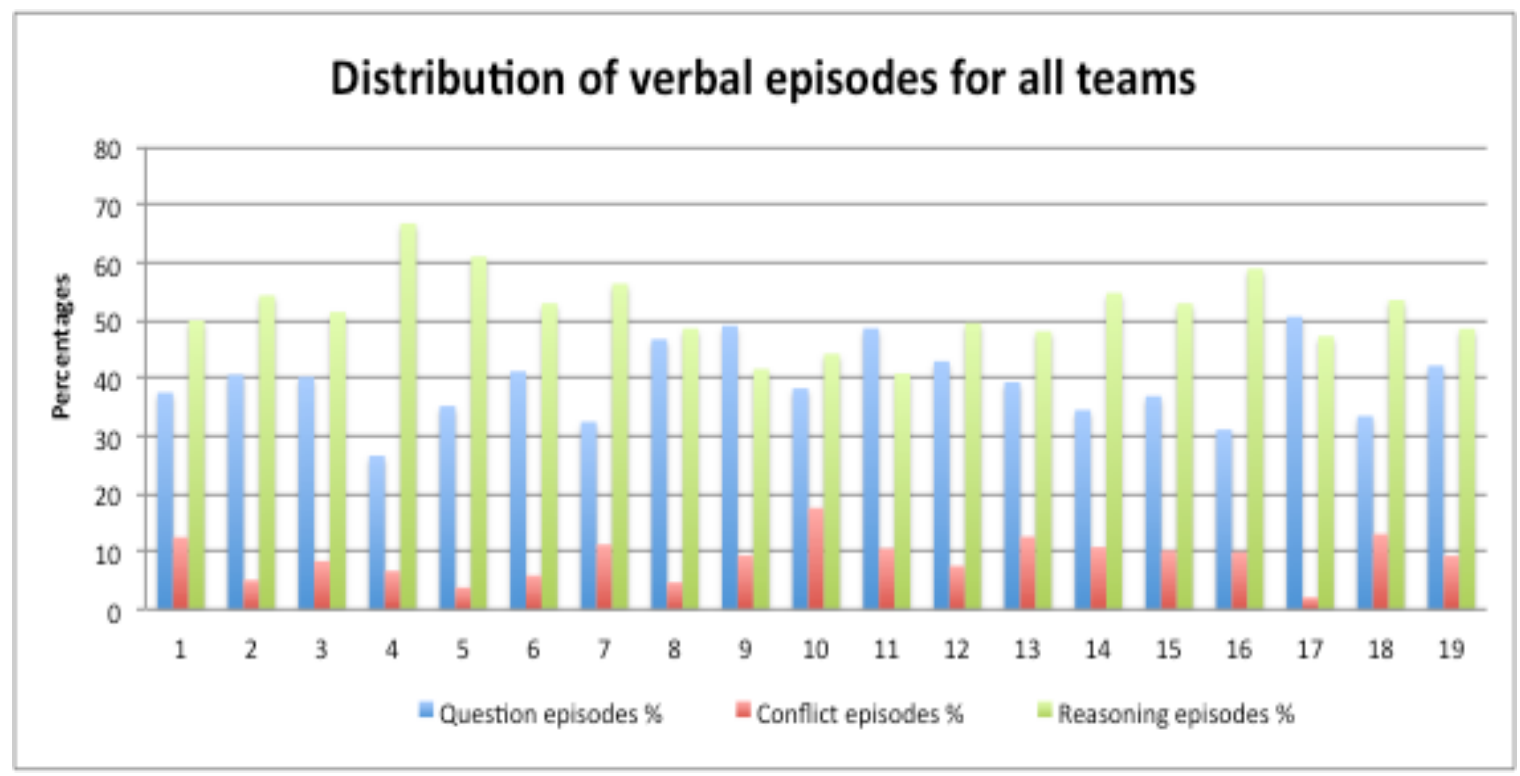

Figure 1. Distribution of all verbal episodes for nineteen teams.

\section{Individual Performance Results}

The linear combination of three types of episodes (question, reasoning, conflict episodes) was significantly related to the individual performance scores, $F(3,69)=3.57, p<.05, r^{2}=.14$. The sample multiple correlation coefficient was .37. Among three types of verbal moves, the question episodes were significant predictors of individual student performance. In addition, "asking questions" was a better predictor than "answering questions" for student performance. Among three types of question episodes, verification and open type questions were significantly correlated with individual performance, for verification $r(71)=.38, p<.05$, and for open $r(71)=$ $.36, p<.05$. While overall conflict was not a significant predictor, generating critical questions was significantly correlated with individual performance, Critical Questions $r(71)=.26, p<.05$.

In terms of percentages, the question episodes were positively correlated with individual performance. However, the percentage of reasoning episodes was negatively correlated with individual performance. In other words, generating or involving relatively more questions rather than reasoning was significantly associated with individual performance. On the other hand, conflict episodes were not significantly correlated with performance.

\section{Team Performance Results}


The relationships between team performance and verbal moves were mixed. First, the reasoning episodes was negatively correlated with the team performance, $r(17)=-.42 p<.05$, and the question episodes was positively correlated $r(17)=.35 p=.07$, but this correlation was not significant at .05 alpha level. Furthermore, there was no meaningful relation between the conflict episodes and team performance.

\section{Discussion}

Our study highlights the critical role of questioning and question episodes in both individual achievement and team performance. Our results indicate that the question episodes were the significant predictor of individual student performance, beyond the reasoning and conflict episodes. Moreover, asking questions rather than answering had a stronger association with performance.

Among the type of question, open and verification type questions were significantly correlated with performance. In terms of team performance, teams that spent more time on question episodes performed better compared to teams that spent more time on reasonign episodes (discourse about data, calculation procedures).

Students spent most of their time on reasoning episodes. Yet, spending more time on reasoning episodes rather than question episodes was negatively related to their team performance. Conflict episodes did not occur frequently, a finding that is aligned with previous work [5]. Hence, the relative effectiveness of conflict episodes was not significantly correlated with performance.

\section{Conclusions}

The study of learning in groups and collaborative teams is an area, which has long been a topic of research interest but still calls for further research. Similar to prior studies, our findings highlight the complexity of social learning and decision-making processes but also suggests that a focus on question asking, especially open questions and verification type questions, can support student achievement and performance. Future research should examine questioning, a practice which is also found to be associated with other critical competencies in engineering such as innovation [11] and design creativity [10], [21], [22] 


\section{References}

[1] K. V Katsikopoulos, "Decision methods for design: insights from psychology," J. Mech. Des., vol. 134, no. 8, p. 84504, 2012.

[2] Z. Sha and J. H. Panchal, "Estimating Local Decision-Making Behavior in Complex Evolutionary Systems," J. Mech. Des., vol. 136, no. 6, p. 61003, 2014.

[3] T.-K. See and K. Lewis, "A formal approach to handling conflicts in multiattribute group decision making," J. Mech. Des., vol. 128, no. 4, pp. 678-688, 2006.

[4] M. T. H. Chi and M. Menekse, "Dialogue patterns that promote learning," in Socializing Intelligence through Talk and Dialogue, L. B. Resnick, C. Asterhan, and S. N. Clarke, Eds. Washington DC: AERA, 2015, pp. 263-274.

[5] S. Purzer, "The Relationship Between Team Discourse, Self-Efficacy, and Individual Achievement: A Sequential Mixed-Methods Study,” J. Eng. Educ., vol. 100, no. 4, pp. 655-679, 2011.

[6] D. Kuhn, “Thinking together and alone,” Educ. Res., p. 0013189X15569530, 2015.

[7] A. Ram, "A theory of questions and question asking," J. Learn. Sci., vol. 1, no. 3-4, pp. 273-318, 1991.

[8] C. Chin and J. Osborne, "Students' questions: a potential resource for teaching and learning science," Stud. Sci. Educ., vol. 44, no. 1, pp. 1-39, 2008.

[9] M. Barak and S. Rafaeli, "On-line question-posing and peer-assessment as means for webbased knowledge sharing in learning," Int. J. Hum. Comput. Stud., vol. 61, no. 1, pp. 84103, 2004.

[10] O. Eris, "Manifestation of divergent-convergent thinking in question asking and decision making processes of design teams: A performance dimension," in Human Behaviour in Design, Springer, 2003, pp. 142-153.

[11] P. D. Mathis, N. D. Fila, and S. Purzer, "Deconstructing the Innovator's DNA," in 2014 ASEE Annual Conference, 2014, pp. 24.354.1-24.354.12.

[12] K. Hogan, "Sociocognitive roles in science group discourse," Int. J. Sci. Educ., vol. 21, no. 8, pp. 855-882, 1999.

[13] A. W. Oliveira and T. D. Sadler, "Interactive patterns and conceptual convergence during student collaborations in science," J. Res. Sci. Teach., vol. 45, no. 5, pp. 634-658, 2008.

[14] M. T. H. Chi, "Self-explaining expository texts: The dual processes of generating inferences and repairing mental models," Adv. Instr. Psychol., vol. 5, pp. 161-238, 2000.

[15] J. Guiller, A. Durndell, and A. Ross, "Peer interaction and critical thinking: Face-to-face or online discussion?," Learn. Instr., vol. 18, no. 2, pp. 187-200, 2008.

[16] V. D. Wall, G. J. Galanes, and S. Love, "Small, task-oriented groups conflict, conflict management, satisfaction, and decision quality," Small Gr. Res., vol. 18, no. 1, pp. 31-55, 1987.

[17] J. M. Kittleson and S. A. Southerland, "The role of discourse in group knowledge construction: A case study of engineering students," J. Res. Sci. Teach., vol. 41, no. 3, pp. 267-293, Mar. 2004.

[18] C. Van Boxtel, J. Van der Linden, and G. Kanselaar, "Collaborative learning tasks and the elaboration of conceptual knowledge," Learn. Instr., vol. 10, no. 4, pp. 311-330, 2000.

[19] N. Saab, W. R. Joolingen, and B. H. A. M. Hout-Wolters, "Communication in collaborative discovery learning," Br. J. Educ. Psychol., vol. 75, no. 4, pp. 603-621, 2005.

[20] G. Erkens and J. Janssen, "Automatic coding of dialogue acts in collaboration protocols," 
Int. J. Comput. Collab. Learn., vol. 3, no. 4, pp. 447-470, 2008.

[21] O. Eris, "Asking generative design questions: a fundamental cognitive mechanism in design thinking," in DS 31: Proceedings of ICED 03, the 14th International Conference on Engineering Design, Stockholm, 2003.

[22] C. Cardoso, Ö. Eris, P. Badke-Schaub, and M. Aurisicchio, "Question asking in design reviews: how does inquiry facilitate the learning interaction?," 2014. 